ORIGINAL ARTICLE

\title{
Aircraft noise around a large international airport and its impact on general health and medication use
}

\author{
E A M Franssen, C M A G van Wiechen, N J D Nagelkerke, E Lebret
}

Occup Environ Med 2004;61:405-413. doi: 10.1136/oem.2002.005488

See end of article for authors' affiliations

Correspondence to:

Correspondence to:
Drs $C$ van Wiechen National Institute for Public Health and the

Environment (RIVM),

Centre for Environmental

Health Research, PO Box

1, Bilthoven $3720 \mathrm{BA}$,

Netherlands;

carla.van.wiechen@

rivm.nl

Accepted

8 September 2003

\begin{abstract}
Aims: To assess the prevalence of general health status, use of sleep medication, and use of medication for cardiovascular diseases, and to study their relation to aircraft noise exposure.

Methods: These health indicators were measured by a cross-sectional survey among 11812 respondents living within a radius of $25 \mathrm{~km}$ around Schiphol airport (Amsterdam).

Results: Adjusted odds ratios ranged from 1.02 to 2.34 per $10 \mathrm{~dB}(A)$ increase in $L_{\text {den }}$. The associations were statistically significant for all indicators, except for use of prescribed sleep medication or sedatives and frequent use of this medication. None of the health indicators were associated with aircraft noise exposure during the night, but use of non-prescribed sleep medication or sedatives was associated with aircraft noise exposure during the late evening $(O R=1.72)$. Vitality related health complaints such as tiredness and headache were associated with aircraft noise, whereas most other physical complaints were not. Odds ratios for the vitality related complaints ranged from 1.16 to 1.47 per $10 \mathrm{~dB}(A)$ increase in $L_{\text {den }}$. A small fraction of the prevalence of poor self rated health (0.13), medication for cardiovascular diseases or increased blood pressure (0.08), and sleep medication or sedatives $(0.22)$ could be attributed to aircraft noise. Although the attributable fraction was highest in the governmentally noise regulated area, aircraft noise had more impact in the non-regulated area, due to the larger population.

Conclusions: Results suggest associations between community exposure to aircraft noise and the health indicators poor general health status, use of sleep medication, and use of medication for cardiovascular diseases.
\end{abstract}

$\mathrm{T}$ he continuing growth of air transportation may put pressure on the environment, especially in densely populated areas. People living near airports are concerned about health effects of aircraft related pollution and safety. These concerns are substantiated by findings that aircraft noise may have adverse health effects such as annoyance, sleep disturbance, and cardiovascular diseases. ${ }^{1-7}$

Since the 1960s many community surveys around airports have been conducted. Fields ${ }^{8}$ identified 521 social surveys, published in English between 1943 and 2000, on residents' reactions to environmental noise in residential areas. Most of these studies measured annoyance. Some also measured general health and medication use and reported associations between self-rated health status or self-reported health complaints and aircraft noise exposure. ${ }^{2-13}$ Several studies found an association between use of medication for sleep or cardiovascular diseases and aircraft noise levels, ${ }^{14-16}$ but others reported no associations. ${ }^{17}$ Knipschild, ${ }^{14}{ }^{18}$ one of the first to study self-reported health problems and use of cardiovascular drugs in a series of community surveys around Schiphol airport, found an increased use of cardiovascular drugs in areas with high aircraft noise levels. He also found a relation between aircraft noise exposure and the contact rate with general practitioners, especially for psychological problems, psychosomatic symptoms, and cardiovascular diseases. A more recent study on the use of medication around Schiphol airport, based on automated pharmacy registrations, suggested a relation between aircraft noise exposure and the use of sedatives. ${ }^{19}$

At the beginning of the 1990s, plans were made to expand Schiphol airport with a fifth runway. Schiphol is situated in a densely populated area on the outskirts of Amsterdam. It is the fourth international airport in
Europe with 432 thousand aircraft movements, 39.5 million passengers, and 1183 thousand tons of freight. ${ }^{20}$ Due to the expansion from four to five runways, the Dutch government initiated the Health Impact Assessment Schiphol Airport (HIAS), a long term research programme on health effects of environmental pollution around Schiphol airport.

The first phase of HIAS was part of an Environmental Impact Assessment (EIA) showing that exposure to aircraft noise caused annoyance, sleep disturbance, cardiovascular disease risk, and reduced performance. ${ }^{21}$ The authors concluded that local air pollution levels were probably not associated with health effects such as respiratory diseases or cancer. Further research was recommended for several health indicators, for example, medication use, birth weight, cardiovascular diseases, annoyance, sleep disturbance, and neurobehavioural effects. This was realised in the second phase of the HIAS. Health impact assessments such as this one are currently considered necessary, ${ }^{4}$ and are required under the EU programme of community action in the field of public health. ${ }^{22}$

Here we present results from a questionnaire survey, which was part of HIAS phase II. ${ }^{23}{ }^{24}$ Its two objectives were: (1) to assess the prevalence of annoyance, sleep disturbance, selfrated general health status, respiratory complaints, medication use, perceived risk, and residential satisfaction in the Schiphol region; and (2) to study the relation of these variables with aircraft noise exposure and/or air pollution. The selection of these health indicators was based on recommendations formulated in phase I of the HIAS and by local environmental action committees. The focus of this article is on general health status, use of sleep medication, and use of medication for cardiovascular diseases in relation to aircraft noise exposure. 


\section{Main messages}

- Exposure to aircraft noise at levels above $50 \mathrm{~dB}(\mathrm{~A}) \mathrm{L}_{\mathrm{den}}$ may contribute to a poorer general health status.

- Exposure to aircraft noise may be a risk factor for cardiovascular diseases.

- Exposure to aircraft noise during the late evening is associated with the intake of non-prescribed sleep medication or sedatives.

- The number of people suffering health effects due to aircraft noise is dominated by the large number of people that is exposed to relatively moderate to low noise levels, not by those exposed to high noise levels.

\section{MATERIALS AND METHODS \\ Study design}

We conducted a postal questionnaire among adults ( 18 years and older) between November 1996 and February 1997 in an area with a radius of 25 kilometres around the airport (fig 1), inhabited by almost 2 million people; approximately 1.5 million of these were aged 18 years and older. The questionnaire comprised questions on annoyance, sleep disturbance, general health status, respiratory complaints, medication use, perceived risk, and residential satisfaction. It also solicited information on potential determinants of these variables, such as personal characteristics, living situation, and smoking behaviour. Questions were derived, where possible, from existing, validated questionnaires.

We used stratified random sampling of 31000 addresses, which were obtained from the Netherlands Post and Telecommunications company. The desired sample size was calculated according to Kirkwood ${ }^{25}$ for two expected effects: annoyance due to noise and respiratory complaints. Background prevalences for annoyance and respiratory complaints were $10 \%$ and $3.6 \%$ respectively. Aircraft noise was assumed to increase the prevalence of annoyance by 25$50 \%$ and air pollution was assumed to increase the prevalence of respiratory complaints by $50-100 \%$. Power calculations were performed for an area with high noise levels $(>35$ Kosten units; for a description of Kosten units refer to the "exposure assessment" section) and one with low levels $(<35 \mathrm{Ke})$ with equal group sizes in each area. The power was $80 \%$ and the confidence limit 5\%. Based on these calculations a random sample of 5000 people would be sufficient. However, fewer people live in high noise areas than in low noise areas; it is desirable that the former should be overrepresented in the sample. The second form of stratification is based on the accuracy required to be able to observe differences in prevalence over time, in areas that at present have low noise levels. Over-representation of these areas is also desirable. On the basis of these considerations it was decided that a net sample size of 10000 people would be required. Given an expected response rate of $25-35 \%$, a random sample of 30000 addresses from a radius of $25 \mathrm{~km}$ around the airport would be needed to achieve this net result.

The sample was stratified by aircraft noise exposure (10 categories) and distance to the centre of the airport (five categories). The stratification was carried out in a geographic information system (Arc/Info 7.2.1), by combining a digital map containing aircraft noise contours with a map containing distance contours. This combined map was again superimposed on a digital map containing address coordinates. The thinly populated areas, closer to the airport and with higher noise levels, contained too few addresses to adequately fill the sample cells. In these cells, all existing addresses were

\section{Policy implications}

- Effects of aircraft noise are not limited to annoyance reactions, but also include other health effects such as poorer general health, cardiovascular diseases, and sleep disturbance.

- Policy measures to reduce community exposure to aircraft noise should not only be concentrated on areas exposed to high aircraft noise levels.

- If expansion of the airport capacity will increase the number of moderate and low exposed people, the overall impact on public health is likely to also increase.

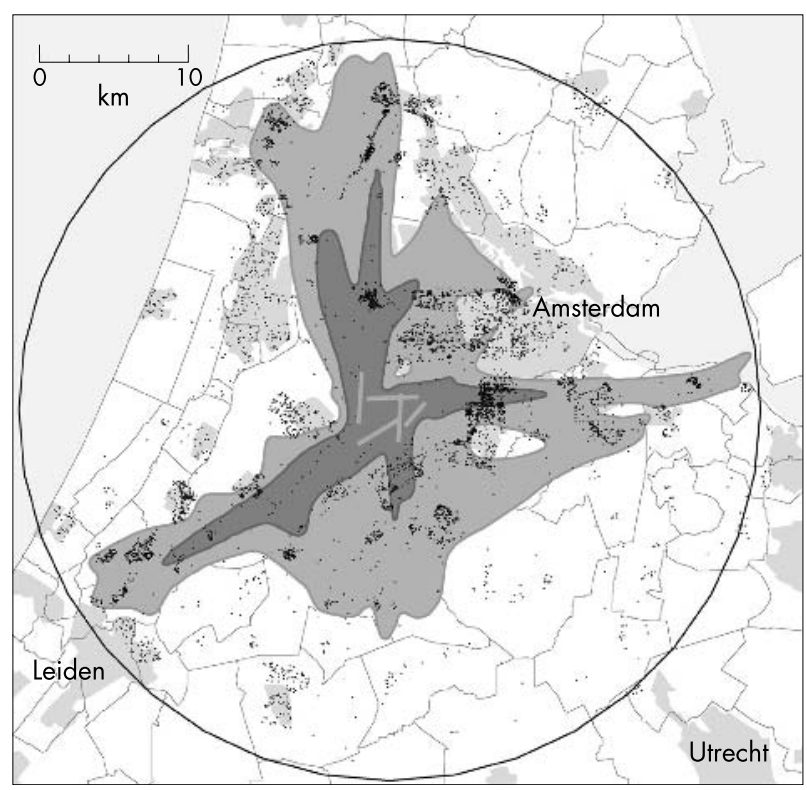

Figure 1 Study area with 20 and 35 Kosten unit contours (1996). The circle represents a distance of 25 kilometres around Schiphol. The dots show the residential locations of the respondents.

included in the sample, and the smaller number of addresses was compensated for in other cells with the same noise levels where possible. Questionnaires were sent to 30216 addresses. Non-respondents received a reminder letter after a few weeks.

\section{Health indicators}

The general health status was measured in two ways, both widely used in (Dutch) health care research:

- With a single question: "How is your health in general?". Most health surveys ask similar kinds of questions, but there is still no standard formulation for this question. We used one that has been applied in Dutch national health surveys since 1983, and can be answered on a five point scale: (1) very good, (2) good, (3) moderate, (4) sometimes good and sometimes bad, (5) bad. For analysis the variable was dichotomised into "good" (categories (1) and (2)) and "poor" (the last three categories). ${ }^{26}$

- With a 13 item questionnaire (VOEG), consisting of a list of health complaints. The VOEG questionnaire was originally designed in the Netherlands to measure stress in industrial situations, ${ }^{27}$ but is currently also commonly applied in general health surveys. ${ }^{28}$ It covers items such as 
physical complaints (for example, back pain), and symptoms reflecting vitality (for example, tiredness, listlessness). Respondents indicate which symptoms were present "lately". The total number of symptoms reported by a respondent is the VOEG score (with a minimum of 0 and a maximum of 13); a higher VOEG score indicates a poorer self-rated health. For analysis the VOEG was dichotomised: respondents with six or more symptoms were defined as having a "poor self-rated health". In addition, each of the 13 items was analysed separately.

We assessed use of medication for cardiovascular diseases or increased blood pressure and use of sleep medication or sedatives, whether on doctor's prescription or as selfmedication. Respondents could indicate which medication was used in the 12 months prior to the moment of questioning. For medication for cardiovascular diseases and increased blood pressure, we only analysed prescribed medication, as this is rarely used without prescription ( $1 \%$ in this study). For sleep medication or sedatives we analysed both prescribed and non-prescribed medication. Respondents could also report the frequency of use of sleep medication or sedatives. This was measured on a four point scale: (1) every night, (2) regularly, (3) occasionally, (4) never. For analysis this variable was dichotomised: respondents who used sleep medication or sedatives "every night" or "regularly" were defined as frequent users, respondents who used these medicines "occasionally" or "never" were defined as nonfrequent users.

\section{Exposure assessment}

The National Aerospace Laboratory, using a mathematical model of the annual exposure to aircraft noise around Schiphol airport calculated aircraft noise levels. Several annual average aircraft noise measures for 1996 were calculated at the geographical location of each respondent's residence. Since we did not have the $\mathrm{x}$ and $\mathrm{y}$ coordinates of the actual residential addresses, we took the closest alternative, being the $\mathrm{x}$ and $\mathrm{y}$ coordinates of the geometric centre of the six digit postal code area of each residential address. These areas cover on average 17 addresses. For the analyses we used the following noise measures: $\mathrm{L}_{\mathrm{den}}$

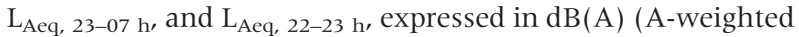
decibels), and the Kosten unit. $\mathrm{L}_{\mathrm{den}}$ (day, evening, night) is an equivalent sound level over 24 hours in which sound levels during the evening (19 00-23 00 hours) are increased by $5 \mathrm{~dB}(\mathrm{~A})$ and those during the night (23 00-07 00 hours) by $10 \mathrm{~dB}(\mathrm{~A})$. As a result of these penalties for the evening and

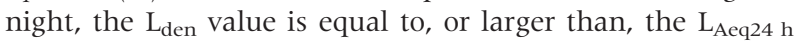
value, the difference depending on the distribution of the traffic over the day, evening, and night period. $\mathrm{L}_{\mathrm{Aeq}}, 23-07 \mathrm{~h}$ and $\mathrm{L}_{\mathrm{Aeq}}, 22-23 \mathrm{~h}$ are also equivalent sound levels, calculated over the corresponding time periods. The Kosten unit is a commonly used measure for aircraft noise in the Netherlands, developed by the Kosten Committee in $1963 .{ }^{29}$ With the fifth runway that became operational at Schiphol airport in January 2003, the Kosten unit is officially replaced by the noise measure $L_{d e n}$. The $L_{d e n}$ value is approximately equal to $(0.5 *$ Kosten unit +41$) .^{30}$

\section{Non-response follow up}

To examine selective non-response, a follow up telephone interview was carried out among 500 non-respondents. The sample of non-respondents was randomly selected from all addresses in the initial sample from which no response was received as of 31 January $1997(\mathrm{n}=17840)$.

These non-respondents were asked for their sociodemographic characteristics (gender, age, education, and country of origin), the reason for not responding, their annoyance due to aircraft noise, their concern about safety because of living close to a large airport, and their attitude regarding the expansion of Schiphol airport. The questions were identical to the corresponding questions in the original, postal questionnaire. Results from this survey indicated that selective non-response was likely. Non-respondents suffered less annoyance due to aircraft noise, were less concerned about airport safety, and had a less negative attitude regarding the expansion of Schiphol. The non-respondent group was less highly educated and comprised more people of foreign origin.

\section{Statistical analysis}

All statistical analyses were performed with SAS 8.02. Observations were suitably re-weighted to take the stratified study design into account, and weighted overall prevalences of the health indicators were calculated. The association between the health indicators and aircraft noise exposure was assessed using a multiple logistic regression model, controlling for potential determinants such as age, sex, education level, country of origin, smoking behaviour, and degree of urbanisation. In the analyses of self-rated health, we also controlled for the number of household members and home ownership. To assess linearity of the relation, the aircraft noise measure was included continuous as well as categorised (in categories of $5 \mathrm{~dB}(\mathrm{~A})$ ). Both prevalences and odds ratios (ORs) were calculated with and without the nonresponse weighting factor (see section on non-response bias), to judge the sensitivity of results to selection bias. In the regression analyses for sleep medication or sedatives (prescribed and non-prescribed) and frequent use of sleep medication or sedatives, we excluded respondents who also took medication for cardiovascular diseases or increased blood pressure, and/or who took medication for rheumatism or painful joints, and/or who regularly worked night shifts. These variables might bias the relation between exposure and response.

\section{Population attributive risks}

To estimate how much of the prevalence of a health effect was attributable to aircraft noise, population attributive risks (PARs) were estimated for the area with aircraft noise levels of 20 Kosten units or more (approximately $\geqslant 50 \mathrm{~dB}(A) L_{\mathrm{den}}$ ), and 35 Kosten units or more (approximately $\geqslant 58 \mathrm{~dB}(\mathrm{~A})$ $\left.L_{d e n}\right)$. The attributable fraction was defined as the prevalence of health effects caused by aircraft noise divided by the overall prevalence. PARs were estimated for poor self-rated health (single question), medication for cardiovascular diseases or increased blood pressure, and prescribed sleep medication or sedatives. Since there was no evidence for threshold levels of noise for health effects, a sensitivity analysis on the noise exposure measure was carried out. The following variants were calculated: (1) the noise level was included in the regression model as a continuous variable, with the reference value of the noise level set to zero, that is, with the assumption that there is no threshold; (2) the noise level was included in the regression model as a continuous variable, with the reference value of the noise level set to 10 Kosten units (approximately $46 \mathrm{~dB}(\mathrm{~A}) \mathrm{L}_{\mathrm{den}}$ ), that is, it is assumed that no health effects result from aircraft noise below a threshold of 10 Kosten units; (3) the noise level was categorised into intervals, with 10 Kosten units or less as reference interval.

\section{Non-response bias}

We conducted a sensitivity analysis to estimate the impact of non-response. Data from a combined data set of respondents $(\mathrm{n}=11812)$ and non-respondents $(\mathrm{n}=271)$ were used to estimate selection bias. We evaluated various prevalence estimates using logistic regression analysis, with "group" as 
Table 1 Number of respondents and chance ( $p$ values, below) to end up in the sample per sample stratum; the number of nonrespondents per exposure stratum are in parentheses

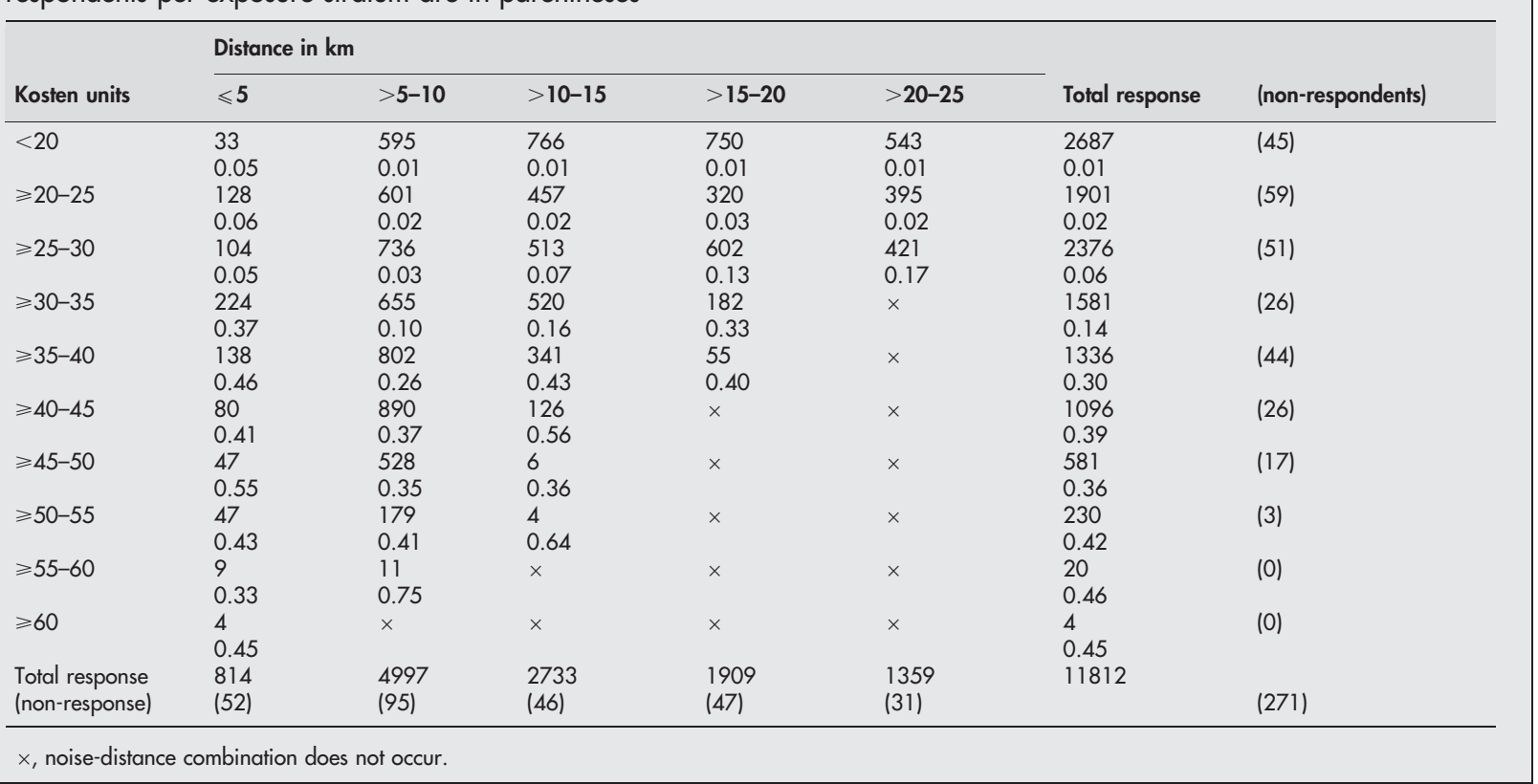

the dependent variable $(\mathrm{l}=$ respondent, $0=$ non-respondent). Five models were estimated, each with a different explanatory variable: noise level, distance to the centre of the airport, annoyance due to aircraft noise, concern about airport safety, and attitude regarding the expansion of Schiphol. Each of the five models was further adjusted for age, gender, education, and country of origin. This resulted in five different weighting factors for each respondent, based on his or her score on the variables in these five models. The weighting factor was 1 divided by the probability $(p)$ of response $\left(\mathrm{W}_{1}\right)$, divided by the average of $\mathrm{W}_{1}$. The nonresponse weighting factors varied from 0.01 to 17.6. This method indicated substantial influence of non-response in the analysis of noise annoyance, ${ }^{23}{ }^{24}$ but only minor influence on the effects published here.

\section{RESULTS}

The final response rate was $39 \%(\mathrm{n}=11812)$. The response rate of the non-response survey was $54 \%(n=271)$. Table 1 shows the distribution of respondents and non-respondents among the exposure strata. Table 2 describes the aircraft noise exposure measures that were used in the analyses. The different noise measures are highly correlated (Pearson's $r>0.90$ ). Table 3 shows the characteristics of the study population. Respondents are evenly distributed between the two sexes. Over $40 \%$ of the respondents are aged $35-54$ years, and nearly half have an intermediate education level. There are few respondents of non-Dutch origin. These variables are more or less evenly distributed among the different noise level categories, except for degree of urbanisation (air traffic is preferably routed across rural area). Table 4 shows prevalences of the health indicators. The overall prevalence of poor self-rated health is comparable to the prevalence in the general Dutch population in 1996 (19\%). ${ }^{31}$ The average VOEG score is 3.1 (SD 2.8), compared to 2.6 in the general Dutch population. ${ }^{32}$ Pain in bones and muscles, feelings of tiredness, and back pain are the most prevalent health complaints $(38-41 \%)$. Pain in the chest or cardiac region, upset stomach, and dizziness are least prevalent (13-14\%). The prevalences of medication use could not be compared to Dutch reference figures, due to differences in the phrasing of questions.
The effect of the non-response weighting factors on the prevalence estimates was assessed, and the differences in estimated prevalences were negligible. In table 4 we show the effect of the weighting factor based on the model with "annoyance due to aircraft noise" as the explanatory variable. It shows that non-response had only minor influence on the results; the overall prevalence varied only $0-2 \%$. Results for the other four models were similar.

\section{Exposure-response relations}

Figures presented here are not weighted for non-response, as use of the non-response weighting factor in our regression models did not affect the results. Table 5 presents the associations between health indicators and aircraft noise exposure measures. Associations with $\mathrm{L}_{\mathrm{den}}$ are all positive and statistically significant, except for prescribed sleep medication or sedatives and its frequent use. The health indicators do not appear to be related to noise exposure during the night $\left(\mathrm{L}_{\text {Aeq, } 23-07 \mathrm{~h}}\right)$. However, the use of nonprescribed sleep medication or sedatives is associated with aircraft noise exposure in the late evening $\left(\mathrm{L}_{\mathrm{Aeq}}, 22-23 \mathrm{~h}\right)$ with an OR of 1.72. Analyses of the separate VOEG items showed statistically significant relations of $\mathrm{L}_{\mathrm{den}}$ with six health complaints (ORs for an increase of $10 \mathrm{~dB}(\mathrm{~A})$ ): shortness of breath $(\mathrm{OR}=1.29,95 \% \mathrm{CI} 1.09$ to 1.53$)$; feelings of tiredness $(\mathrm{OR}=1.34,95 \%$ CI 1.17 to 1.53$)$; headache $(\mathrm{OR}=1.16,95 \%$ CI 1.01 to 1.34); tired sooner than considered normal $(\mathrm{OR}=1.47,95 \% \mathrm{CI} 1.26$ to 1.70$)$; listlessness $(\mathrm{OR}=1.17$, 95\% CI 1.01 to 1.36); and tired and not fully rested in the morning $(\mathrm{OR}=1.20,95 \% \mathrm{CI} 1.03$ to 1.41$)$. For the remaining seven complaints the ORs were lower, ranging from 0.99 to

Table 2 Description of the aircraft noise exposure measures in the study population

\begin{tabular}{llll}
\hline Exposure measure & Range & Average & SD \\
\hline$L_{\text {den }}$ & $41-76 \mathrm{~dB}(\mathrm{~A})$ & 51.3 & 3.1 \\
$\mathrm{~L}_{\text {Aeq, 22-23 } \mathrm{h}}$ & $36-70 \mathrm{~dB}(\mathrm{~A})$ & 44.3 & 4.1 \\
$\mathrm{~L}_{\text {Aeq, 23-07 } \mathrm{h}}$ & $32-65 \mathrm{~dB}(\mathrm{~A})$ & 37.9 & 4.0 \\
Kosten units & 0-64 Kosten units & 17.3 & 6.8 \\
\hline
\end{tabular}




\begin{tabular}{|c|c|c|c|c|c|c|}
\hline$L_{\text {den }}$ in $d B(A)$ & $<50$ & $50-55$ & $55-60$ & $\geqslant 60$ & Total $^{*}$ & Total† \\
\hline \multicolumn{7}{|l|}{$\operatorname{Sex}(n=11601)$} \\
\hline Male & 50 & 53 & 54 & 53 & 52 & 49 \\
\hline Female & 50 & 47 & 46 & 47 & 48 & 51 \\
\hline \multicolumn{7}{|l|}{ Age $(n=11481)$} \\
\hline $18-34$ & 30 & 28 & 21 & 24 & 28 & 34 \\
\hline $35-54$ & 39 & 40 & 38 & 40 & 40 & 38 \\
\hline $55-74$ & 24 & 26 & 33 & 28 & 26 & 21 \\
\hline$\geqslant 75$ & 7 & 6 & 8 & 8 & 6 & 8 \\
\hline \multicolumn{7}{|l|}{ Education level $(n=11220)$} \\
\hline None and lower & 17 & 19 & 21 & 21 & 18 & \\
\hline $\begin{array}{l}\text { Intermediate } \\
\text {. }\end{array}$ & 46 & 46 & 50 & 48 & 47 & \\
\hline Higher & 37 & 35 & 29 & 31 & 35 & \\
\hline \multicolumn{7}{|c|}{ Country of origin $(n=11335)$} \\
\hline Netherlands & 95 & 94 & 94 & 96 & 95 & \\
\hline Other & 5 & 6 & 6 & 4 & 5 & \\
\hline \multicolumn{7}{|c|}{ Smoking behaviour $(n=11509)$} \\
\hline Never smoked & 37 & 37 & 39 & 40 & 37 & \\
\hline Ex-smoker & 34 & 34 & 35 & 33 & 34 & \\
\hline Smoker & 29 & 29 & 26 & 27 & 29 & \\
\hline \multicolumn{7}{|c|}{ Degree of urbanisation $(n=11812)$} \\
\hline Rural/slightly urban & 26 & 15 & 35 & 54 & 20 & \\
\hline Urban/strongly urban & 39 & 54 & 35 & 18 & 48 & \\
\hline Extremely urban & 35 & 31 & 30 & 28 & 32 & \\
\hline
\end{tabular}

1.17, and not statistically significant. Table 6 shows the relation of the health indicators with $L_{d e n}$ when this noise measure was categorised. The ORs tend to rise with increasing noise levels, but differences between the categories are not statistically significant. When the regression analyses for sleep medication or sedatives (prescribed, non-prescribed, and frequent use) were repeated without excluding the possibly modifying variables described under "materials and methods", similar results were obtained. In addition to health determinants, degree of urbanisation was also considered a potential determinant. However, omitting this determinant from our analyses did not substantially alter the results.

\section{Population attributive risks}

Table 7 shows results of the PAR analyses. The PARs vary for the three models tested. The PARs are naturally highest when the noise measure is included in the model as a continuous variable with reference value set to zero, and the model with a categorised noise measure gives the lowest PARs. Due to the low precision of the relation between exposure and response in areas with low aircraft noise exposure, the figures for the 20 Kosten unit zone show a wide range in the estimates. The confidence interval on either side of the point estimate is so wide that negative values are possible. In this zone the maximum attributable fraction for aircraft noise was 0.13 for poor self-rated health, 0.08 for medication for cardiovascular diseases or increased blood pressure, and 0.22 for sleep medication or sedatives.

\section{DISCUSSION}

Our main aims were to assess the prevalence of health indicators in the Schiphol region, in relation to aircraft noise

\begin{tabular}{|c|c|c|c|}
\hline & $\mathbf{n}_{\text {effect }}$ & $\begin{array}{l}\% \text { overall } \\
\text { prevalence }\end{array}$ & $\begin{array}{l}\% \text { after non- } \\
\text { response } \\
\text { weighting }\end{array}$ \\
\hline Poor self-rated health (based on single question) & 2301 & 20 & 20 \\
\hline Poor self-rated health (based on VOEG* score) & 2157 & 20 & 19 \\
\hline & & & \\
\hline Bloated or heavy feeling in the gastric region & 2149 & 19 & 18 \\
\hline Shortness of breath & 2105 & 19 & 19 \\
\hline Pain in the chest or cardiac region & 1412 & 13 & 13 \\
\hline Pain in bones and muscles & 4240 & 38 & 38 \\
\hline Feelings of tiredness & 4431 & 40 & 38 \\
\hline Headache & 3786 & 34 & 33 \\
\hline Back pain & 4643 & 41 & 41 \\
\hline Upset stomach & 1582 & 14 & 14 \\
\hline Benumbed feeling or tingling in limbs & 2584 & 23 & 24 \\
\hline Tired sooner than considered normal & 2805 & 25 & 24 \\
\hline Dizziness & 1524 & 14 & 14 \\
\hline Listlessness & 2866 & 26 & 25 \\
\hline Tired and not fully rested in the morning & 2595 & 23 & 22 \\
\hline $\begin{array}{l}\text { Use of medication for cardiovascular diseases or increased } \\
\text { blood pressure }\end{array}$ & 1750 & 15 & 17 \\
\hline Use of prescribed sleep medication or sedatives & 1231 & 10 & 11 \\
\hline Use of non-prescribed sleep medication or sedatives & 647 & 5 & 5 \\
\hline Frequent use of sleep medication or sedatives & 528 & 5 & 5 \\
\hline
\end{tabular}


Table 5 Odds ratios (OR) and 95\% confidence intervals $(\mathrm{Cl})$ after multiple logistic regression of health indicators, in relation to various noise exposure measures per $10 \mathrm{~dB}(\mathrm{~A})$ increase in noise levels, controlling for potential determinants

\begin{tabular}{|c|c|c|c|c|c|}
\hline Health indicator & $n_{\text {total }}$ & $\mathbf{n}_{\text {effect }}$ & Noise measure & OR & $95 \% \mathrm{Cl}$ \\
\hline $\begin{array}{l}\text { Poor self-rated health } \\
\text { (single question) } \\
\text { Poor self-rated health } \\
\text { (VOEG score) } \\
\text { Medication for cardiovascular diseases/increased blood } \\
\text { pressure } \\
\text { Prescribed sleep medication or sedatives }\end{array}$ & $\begin{array}{l}10412 \\
9887 \\
10105 \\
7240 \\
7240 \\
7175\end{array}$ & $\begin{array}{l}1969 \\
1871 \\
1316 \\
516\end{array}$ & 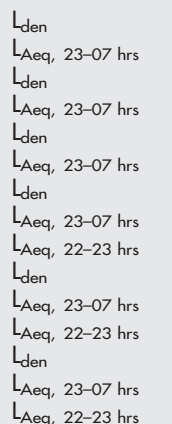 & $\begin{array}{l}1.23 \\
1.05 \\
1.21 \\
1.08 \\
1.30 \\
1.13 \\
1.25 \\
0.91 \\
1.26 \\
2.34 \\
1.20 \\
1.72 \\
1.02 \\
1.36 \\
1.15\end{array}$ & $\begin{array}{l}1.04 \text { to } 1.46 \\
0.91 \text { to } 1.22 \\
1.02 \text { to } 1.43 \\
0.94 \text { to } 1.25 \\
1.06 \text { to } 1.60 \\
0.94 \text { to } 1.35 \\
0.93 \text { to } 1.68 \\
0.70 \text { to } 1.18 \\
0.99 \text { to } 1.60 \\
1.63 \text { to } 3.35 \\
0.87 \text { to } 1.65 \\
1.27 \text { to } 2.32 \\
0.63 \text { to } 1.65 \\
0.91 \text { to } 2.04 \\
0.78 \text { to } 1.70\end{array}$ \\
\hline
\end{tabular}

exposure, as a baseline for monitoring future changes in health status due to the expansion of Schiphol airport and changing exposure patterns. The prevalences of the health indicators in the research area were similar to available reference figures for the Dutch population. Despite "normal" prevalences, the risks of both poor self-rated health and of medication use for sleep and cardiovascular diseases increased with aircraft noise levels.

The location of a large international airport may influence the social structure of the population, for example by lowering house prices, and selecting lower social classes with poorer health status. If so, the effects of aircraft noise would be overestimated. In studying the associations between the health indicators and aircraft noise exposure we controlled for a number of potential health determinants, such as lifestyle, personal characteristics, and social economical status. However, there may also be selection effects in the other direction, for example when sensitive subjects have moved out of the high noise areas, which leads to underestimating the effects of noise. ${ }^{33}$ Since it is difficult to study selection in a cross-sectional design, the impact of selection on the results of this study cannot be estimated. Therefore, conclusions on the causality of associations have to be tentative. However, there are no indications that these phenomena play a role around Schiphol airport. Another, related, drawback of a cross-sectional study is that one cannot determine whether (accumulation of) exposure preceded the reported health complaints. ${ }^{34}{ }^{35}$ To minimise this problem retrospective exposure data should be collected. The main aim of this study, however, was to assess baseline prevalence data for monitoring future (changes in) health status. From this perspective detailed estimation of retrospective exposure was not needed.

Proper assessment of subjects' exposure levels is of great importance. Besides aircraft noise, people are exposed to other noises, for example, noise at work, which could be the main reason for health effects or at least interact with residential noise. Also, exposure history plays a role in the development of health effects. We obtained information on retrospective exposure and exposure at work by asking people

Table 6 Odds ratios (OR) and 95\% confidence intervals (Cl) after multiple logistic regression of health indicators per category of $L_{\text {den, }}$ controlling for age, sex, education level, country of origin, smoking behaviour, and degree of urbanisation

\begin{tabular}{|c|c|c|c|c|c|}
\hline Health indicator & $L_{\text {den }}$ in $d B(A)$ & $n_{\text {total }}$ & $\mathbf{n}_{\text {effect }}$ & OR & $95 \% \mathrm{Cl}$ \\
\hline Poor self-rated health & $<50$ & 3012 & 519 & $1.00^{*}$ & \\
\hline \multirow[t]{3}{*}{ (single question) } & $50-55$ & 6505 & 1266 & 1.09 & 0.97 to 1.23 \\
\hline & $55-60$ & 786 & 160 & 1.01 & 0.82 to 1.25 \\
\hline & $\geqslant 60$ & 109 & 24 & 1.30 & 0.79 to 2.12 \\
\hline Poor self-rated health & $<50$ & 2836 & 508 & $1.00^{*}$ & \\
\hline \multirow[t]{3}{*}{ (VOEG score) } & $50-55$ & 6208 & 1183 & 1.07 & 0.95 to 1.21 \\
\hline & $55-60$ & 741 & 154 & 1.13 & 0.92 to 1.40 \\
\hline & $\geqslant 60$ & 102 & 26 & 1.61 & 1.01 to 2.56 \\
\hline Medication for cardiovascular diseases/ & $<50$ & 2935 & 334 & $1.00^{*}$ & \\
\hline \multirow[t]{3}{*}{ increased blood pressure } & $50-55$ & 6279 & 830 & 1.18 & 1.01 to 1.38 \\
\hline & $55-60$ & 780 & 134 & 1.26 & 0.98 to 1.61 \\
\hline & $\geqslant 60$ & 111 & 18 & 1.22 & 0.67 to 2.21 \\
\hline \multirow[t]{4}{*}{ Prescribed sleep medication or sedatives } & $<50$ & 2173 & 141 & $1.00^{*}$ & \\
\hline & $50-55$ & 4449 & 326 & 1.15 & 0.93 to 1.42 \\
\hline & $55-60$ & 541 & 42 & 1.13 & 0.78 to 1.64 \\
\hline & $\geqslant 60$ & 77 & 7 & 1.52 & 0.67 to 3.42 \\
\hline \multirow{4}{*}{ Non-prescribed sleep medication or sedatives } & $<50$ & 2173 & 70 & $1.00^{*}$ & \\
\hline & $50-55$ & 4449 & 203 & 1.59 & 1.20 to 2.11 \\
\hline & $55-60$ & 541 & 31 & 1.89 & 1.21 to 2.95 \\
\hline & $\geqslant 60$ & 77 & 5 & 2.02 & 0.77 to 5.30 \\
\hline \multirow[t]{4}{*}{ Frequent use of sleep medication or sedatives } & $<50$ & 2159 & 58 & $1.00^{*}$ & \\
\hline & $50-55$ & 4402 & 110 & 0.91 & 0.65 to 1.27 \\
\hline & $55-60$ & 539 & 18 & 1.12 & 0.64 to 1.95 \\
\hline & $\geqslant 60$ & 75 & 3 & 1.66 & 0.50 to 5.50 \\
\hline
\end{tabular}


Table 7 Percentage of poor self-rated health and medication use which is attributable to aircraft noise, in areas exposed to 20 Kosten units or more ${ }^{*}$, and 35 Kosten units or more $†$

\begin{tabular}{|c|c|c|c|}
\hline Variable & $\begin{array}{l}\text { Percentage of } \\
\text { people reporting } \\
\text { health effect }\end{array}$ & $\begin{array}{l}\text { Aftribution to aircraft } \\
\text { noise }(\%) \text {, range of } 3 \\
\text { models }\end{array}$ & $\begin{array}{l}\text { Aftributable number in } \\
\text { population age } \geqslant 18 \\
\text { years }\end{array}$ \\
\hline \multicolumn{4}{|l|}{ Poor self-rated health } \\
\hline$\geqslant 20$ Kosten units* & 21 & -0.4 to 2.8 & -1500 to 10400 \\
\hline$\geqslant 35$ Kosten units $\dagger$ & 21 & 2.3 to 4.4 & 500 to 1000 \\
\hline \multicolumn{4}{|c|}{$\begin{array}{l}\text { Use of medication for cardiovascular } \\
\text { diseases or increased blood pressure }\end{array}$} \\
\hline$\geqslant 20$ Kosten units & 17 & 0.6 to 1.4 & 2200 to 5200 \\
\hline \multirow{2}{*}{\multicolumn{4}{|c|}{$\begin{array}{l}\text { Use of prescribed sleep medication or } \\
\text { sedatives }\end{array}$}} \\
\hline & & & \\
\hline$\geqslant 20$ Kosten units & 10 & 1.2 to 2.2 & 4400 to 8100 \\
\hline$\geqslant 35$ Kosten units & 11 & 2.6 to 3.6 & 600 to 800 \\
\hline
\end{tabular}

how long they had lived in their present house and neighbourhood and to what extent they were exposed to aircraft noise at work. The average residential time in the house and neighbourhood was $14( \pm 12)$ and $17( \pm 15)$ years, respectively; $51 \%$ of the respondents had lived longer than 10 years in their neighbourhood. About $6 \%$ of the respondents indicated that they were highly exposed to aircraft noise at work. However, these questions are only a proxy for past exposure, and some misclassification cannot be ruled out. This might under- or over-estimate the effects of aircraft noise on health, depending on whether previous exposure was higher or lower than the exposure assessed at the time of study.

The geo-referencing of individuals to specific locations, instead of larger regions, decreases the chance of nondifferential misclassification with respect to exposure. ${ }^{36}$ In this survey, we geo-referenced subjects using the geometric centre of six digit postal code areas (PCAs) of subjects' residential addresses. These PCAs merely cover parts of streets in high density areas. To investigate its accuracy in less populated areas, we examined those addresses in the study population that were situated in the least densely populated areas. Of all respondents, $12 \%$ lived in six digit PCAs with a geometric centre that was more than 100 metres away from the nearest six digit PCA. Only 3\% lived in six digit PCAs of which this distance was more than 200 metres. Since these addresses were evenly spread across the whole research area, misclassification in this group was assumed minor and unlikely to have a considerable impact on the results.

To attain the objectives of our study, we targeted approximately 10000 completed questionnaires, but as the final response rate $(39 \%)$ was higher than the expected rate of $25-35 \%$ our actual sample was larger. Nevertheless, the non-response group was still large enough to potentially cause under- or over-estimation of prevalences. In the analysis of noise annoyance, sensitivity analysis showed substantial influence of non-response on the prevalence. Although sensitivity analysis showed that weighting for nonresponse had little effect on estimates presented here, we cannot entirely exclude non-response bias. For example, we may have omitted variables in the non-response survey that explain differences between respondents and non-respondents. If non-response bias was still present, it may have affected the prevalences and PARs, but is unlikely to have substantially affected the exposure-response relations.

We carried out stratified random sampling. Observations were re-weighted to take the stratified study design into account. However, when comparing the distribution of age and sex in the respondents with the distribution of age and sex in the study area, the younger age group (18-34 years) is under-represented, while the older age group (55-74 years) is slightly over-represented. This is a common feature in these types of surveys. The distribution of sex is comparable in both groups, but there might be some bias due to difference in age distribution. This may have slightly overestimated the prevalences. However, an effect on the exposure-response relations and PARs is not expected, since these were adjusted for age.

Regression analyses of the two general health indicators gave consistent results. Both the single question and the VOEG were associated with annual average aircraft noise levels $\left(\mathrm{L}_{\mathrm{den}}\right)$. Analysis of the separate health complaints of the VOEG showed that mainly vitality related health complaints, such as tiredness and headache, were associated with aircraft noise exposure. The use of non-prescribed sleep medication or sedatives was associated with aircraft noise exposure during the late evening $\left(\mathrm{L}_{\mathrm{Aeq}}, 22-23 \mathrm{~h}\right)$, but not with the exposure during the night $\left(\mathrm{L}_{\mathrm{Aeq}}, 23-07 \mathrm{~h}\right)$. This suggests that exposure to aircraft noise at times that people go to bed stimulates the use of sleep medication or sedatives. The use of prescribed sleep medication or sedatives was positively related to $\mathrm{L}_{\mathrm{den}}$ and $\mathrm{L}_{\mathrm{Aeq}, 22-23 \mathrm{~h}}$ (OR 1.25 and 1.26 , respectively), but these ORs were not statistically significant. Van Willigenburg and colleagues, ${ }^{19}$ who studied the use of prescribed sleep medication by pharmacy registration data found that the use of prescribed sleep medication was associated with aircraft noise exposure. The increased tendency to use non-prescribed sleep medication might be due to the fact that people rarely visit their general practitioner for noise related sleep problems. They might consider their sleep problems of minor importance and therefore prescription of stronger sedatives by a general practitioner unnecessary. The prevalence of prescribed drugs might be determined by other determinants, for example, the prescription behaviour of general practitioners. They might tend to not easily prescribe sleep medication for sleep complaints due to aircraft noise, which may mask the effects of aircraft noise.

PAR analyses provided estimates of the number of people in the study area suffering health effects due to aircraft noise exposure, and thereby the potential health gain of removing noise exposure. These analyses assume that the statistical association between the noise level and the effect reflects a causal relation and is not due to confounding, for example. The estimates proved sensitive to assumptions about threshold levels and the scale of measurement of noise levels (continuous versus intervals). From these PAR calculations, we estimated that between a few hundred and about one thousand people, living in the area with noise levels of 35 Kosten units or more, reported health effects. Until recently, the 35 Kosten unit zone was the area for which most 
governmental policies were formulated and regulations applied. PAR estimates for the area with noise levels of 2035 Kosten units indicate that thousands of people are affected. If exposure-response relations are also applied in areas with noise levels $<20$ Kosten units, the number of people with health effects due to aircraft noise in the total research area would be two to three times higher than that in the area $\geqslant 20$ Kosten units. It is worth noting that the number of people suffering these effects is dominated by the large number of people who are exposed to relatively moderate to low noise levels, not by those exposed to high noise levels.

Our findings are broadly consistent with what has been reported in the literature..$^{29-1418}$ However, direct comparison of our results with those from other noise effects surveys is hampered by, for example, differences in phrasing and scoring of questions, different outcome measures or risk estimates, and different exposure measures. To improve comparability of various noise effects surveys in the future, the International Commission on the Biological Effects of Noise (ICBEN, Team No. 6: community response) has set the long term goal of developing questionnaire guidelines for noise effects research in social surveys. As a start, the German Ruhr University has developed a database of questionnaires on noise effects ${ }^{37}$ to provide researchers a means to compare the operationalisation of health outcomes and confounding or moderating variables. Without further standardisation of research, inter-study and international comparisons will remain difficult.

In conclusion, we found associations between health indicators (general health status, use of medication for cardiovascular diseases or increased blood pressure, and use of sleep medication or sedatives) and the aircraft noise exposure measure $\mathrm{L}_{\mathrm{den}}$. None of the health indicators were associated with aircraft noise exposure during the night $\left(\mathrm{L}_{\mathrm{Aeq}}, 23-07 \mathrm{~h}\right)$, but use of non-prescribed sleep medication or sedatives was associated with aircraft noise exposure during the late evening $\left(\mathrm{L}_{\mathrm{Aeq}, 22-23 \mathrm{~h}}\right)$. Further, vitality related health complaints such as tiredness and headache were associated with aircraft noise, whereas most other physical complaints were not. In the area with aircraft noise exposure levels $\geqslant 20$ Kosten units, a small fraction of the prevalence of poor selfrated health $(0.13)$, medication for cardiovascular diseases or increased blood pressure $(0.08)$, and sleep medication or sedatives (0.22) could be attributed to aircraft noise. Although the attributable fraction was highest in the governmentally noise regulated area, aircraft noise had more impact in the non-regulated area, due to the larger population exposed.

\section{ACKNOWLEDGEMENTS}

The study was commissioned by three Dutch Ministries: Housing, Spatial Planning and the Environment; Public Health, Welfare and Sport; Transport, Public Works and Water Management. It was conducted by the National Institute for Public Health and the Environment (RIVM) and the Netherlands Organisation for Applied Scientific Research-Prevention and Health (TNO-PG).

\section{Authors' affiliations}

E A M Franssen, C M A G van Wiechen, N J D Nagelkerke, E Lebret, National Institute for Public Health and the Environment (RIVM), Centre for Environmental Health Research, Bilthoven, Netherlands

\section{REFERENCES}

1 Berglund B, Lindvall T, eds. Community noise. Document prepared for the World Health Organisation. Archives of the Centre for Sensory Research 1995;2:1-195

2 Morrell S, Taylor R, Lylu D. A review of health effects of aircraft. Aust NZ J Public Health 1997;21:221-36.
3 Passchier-Vermeer W, Passchier WF. Noise exposure and public health Environ Health Perspect 2000;108(suppl 1): 123-31.

4 Passchier W, Knottnerus A, Albering $\mathrm{H}$, et al. Public health impact of large airports. Rev Environ Health 2000;15:83-96.

5 Porter ND, Flindell IH, Berry BF. Health effect-based noise assessment methods: a review and feasibility study. NPL Report CMAM 16. Teddington: National Physical Laboratory, 1998.

6 Rosenlund M, Berglind N, Pershagen G, et al. Increased prevalence of hypertension in a population exposed to aircraft noise. Occup Environ Med 2001:58:769-73.

7 Stansfeld S, Haines $M$, Brown B. Noise and health in the urban environment. Rev Environ Health 2000;15:43-82.

8 Fields JM. An updated catalog of 521 social surveys of residents' reactions to environmental noise (1943-2000). NASA/CR-2001-211257. Washington, DC: National Aeronautics and Space Administration, 2001

9 Hattori M. A field study of health effects of aircraft noise in adults around Komatsu Air Base. Nippon Koshu Eisei Zasshi 2000;47:20-31 [English abstract].

10 Hiramatsu K, Yamamoto T, Taira K, et al. A survey on health effects due to aircraft noise on residents living around Kadena air base in the Ryukyus. Journal of Sound and Vibration 1997;205:451-60.

11 Meister EA, Donatelle RJ. The impact of commercial-aircraft noise on human health: a neighborhood study in metropolitan Minnesota. J Environ Health 2000;63(4):9-15.

12 Smith A, Nutt D, Wilson S, et al. Noise and insomnia: a study of community noise exposure, sleep disturbance, noise sensitivity and subjective reports of health. Centres for Occupational and Health Psychology, Cardiff University; Psychopharmacology Unit, University of Bristol, 2002.

13 Tarnopolsky A, Watkins G, Hand DJ. Aircraft noise and mental health: I. prevalence of individual symptoms. Psychol Med 1980;10:683-98.

14 Knipschild P, Oudshoorn N. VII. Medical effects of aircraft noise: drug survey. Int Arch Occup Environ Health 1977:40:197-200.

15 Meier HP, Müller R. Tablettenkonsum als reaktion auf Lärm [Medicine use due to noise]. Soz Preventiv Med 1975;20:57-63 [in German].

16 Vallet $M$, Champelovier $P$, Charlot $B$. La consommation de somniferes et de medicaments destines aux troubles cardiovasculaires, par les riverains de grandes routes et $d^{\prime}$ aeroports [Use of medication for sleep and cardiovascular diseases, in populations living close to motorways and airports]. Med Et Hyg 1986;44:53150-3 [in French].

17 Watkins G Tarnopolsky A, Jenkins LM. Aircraft noise and mental health: II. Use of medicines and health care services. Psychol Med 1981;11:155-68.

18 Knipschild P VI. Medical effects of aircraft noise: general practice survey. Int Arch Occup Environ Health 1977;40:191-6.

19 Van Willigenburg APP, Franssen EAM, Lebret E, et al. Geneesmiddelengebruik als indicator voor effecten van milieuverontreiniging; een studie in de regio Schiphol [Medication use as indicator for effects of environmental pollution: a study in the Schiphol region]. Utrecht: State University of Utrecht (RUU); Bilthoven: National Institute for Public Health and the Environment (RIVM), 1996 [in Dutch].

20 Schiphol Group. Statistical Annual Review, 2001. Available: www.schiphol.nl/media/pdf/Vervoersstatistiek/Statjv.pdf [in Dutch]

21 Franssen EAM, Staatsen BAM, Lebret E. Assessing health consequences in an environmental impact assessment. The case of Amsterdam Airport Schiphol. Environmental Impact Assessment Review 2002;22:633-53.

22 Communication from the Commission on Impact Assessment, Brussels 05/06/ 2002 and Decision No. 1786/2002/ of 23 September 2002. Adopting a programme of Community action in the field of public health (2003-2008) Official Journal of the European Communities, 9.10.2002.

23 TNO-PG and RIVM. Hinder, slaapverstoring, gezondheids- en belevingsaspecten in de regio Schiphol, resultaten van een vragenlijstonderzoek [Annoyance, sleep disturbance, health aspects, perceived risk, and residential satisfaction around Schiphol airport; results of a questionnaire survey]. Report numbers: TNO-PG: 98.039; RIVM: 441520010. Leiden: Netherlands Organisation for Applied Scientific Research (TNO-PG); Bilthoven: National Institute for Public Health and the Environment (RIVM), 1998 [in Dutch].

24 TNO-PG and RIVM. Annoyance, sleep disturbance, health aspects, perceived risk, and residential satisfaction around Schiphol airport; results of a questionnaire survey. Summary. Report numbers: TNO-PG: 98.052; RIVM: 441520011 . Leiden: Netherlands Organisation for Applied Scientific Research (TNO-PG); Bilthoven: National Institute for Public Health and the Environment (RIVM), 1999.

25 Kirkwood BR. Essentials of medical statistics. London, Oxford: Blackwell Scientific Publications, 1991.

26 Van Sonsbeek JLA. Het eigen oordeel van de gezondheid, methodische effecten bii het gezondheidsoordeel in gezondheidsenquêtes [Self-rated general health status, methodological effects of self-rating in health surveys]. Maandbericht Gezondheid 1991;12:15-23 [in Dutch].

27 Dirken JM. Arbeid en stress; het vaststellen van aanpassingsproblemen in werksituaties [Labour and stress; to assess problems in adaptability at the workplace]. Groningen: H.D. Tjeenk Willink, 1967 [in Dutch].

28 Van Sonsbeek JLA. Vertel me wat er aan scheelt: betekenis en methodische aspecten van enquêtevragen naar de gezondheid [PhD thesis: Tell me what's wrong: the meaning and methodological aspects of health questions in surveys]. Den Haag: CBS, 1996 [in Dutch].

29 Adviescommissie geluidhinder door vliegtuigen [Advisory committee on noise annoyance due to aircraft]. Geluidhinder door vliegtuigen [Noise annoyance due to aircraft]. Delft: Netherlands Organisation for Applied Scientific Research (TNO), 1967 [in Dutch]

30 Dassen AGM, Dolmans JHJ, Jabben J, et al. Geluid in de viifde milieuverkenning, achtergronden [Background report to the fifth 
environmental outlook: noise]. Report number 408129009 . Bilthoven: National Institute for Public Health and the Environment (RIVM), 2000 [in Dutch].

31 Centraal Bureau voor de Statistiek [Statistics Netherlands]. Trendciifers: gezondheidstoestand van de Nederlandse bevolking, vanaf 1981 [Trend figures: health state of the Dutch population, since 1981]. Heerlen: Centraal Bureau voor de Statistiek, 1997 [in Dutch].

32 Centraal Bureau voor de Statistiek [Statistics Netherlands]. Kernciifers: de leefsituatie van de Nederlandse bevolking [Core figures: living conditions of the Dutch population]. Heerlen: Centraal Bureau voor de Statistiek, 1993 [in Dutch].

33 Babisch W. Epidemiological studies of cardiovascular effects of traffic noise. In: Noise effects '98. Vol. 1. Proceedings of Inter-Noise 1996: The 1996
International Congress on Noise Control Engineering, 30 July-2 August, Liverpool, UK. St Albans: Institute of Acoustics, 1996:2177-88.

34 Morgenstern $\mathrm{H}$, Thomas DC. Principles of study design in environmental epidemiology. Environ Health Perspect 1993;101(suppl 4):23-8.

35 Rothman KJ, Greenland S. Modern epidemiology. Philadelphia: Lippincott Williams \& Wilkins, 1998.

36 Dearwent SM, Jacobs RR, Halbert JB. Locational uncertainty in georeferencing public health datasets. Journal of Exposure Analysis and Environmental Epidemiology 2001;11:329-34.

37 Ecological Noise Research Work Group 2000. Noise Questionnaire Database. Bochum, Germany: Ruhr University, Department of Psychology. Available: http://www.eco.psy.ruhr-uni-bochum.de/nqd [still in progress, updated frequently].

\section{$\mathrm{ECHO}$}

\section{Workplace based faecal occult blood screening}

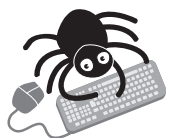

Please visit the Occupational and

Environmental Medicine website [www. occenvmed. com] for a link to the full text of this article.
Dopulation screening using faecal occult blood tests may increase the rate of detection of early stage colorectal tumours and reductions in mortality of $15 \%, 18 \%$, and $33 \%$ have been shown in three large studies. Screening programmes based on general practices have had low rates of acceptance. It has been suggested that on-site health education might increase compliance rates in workplace based programmes, but a study at a large engineering company in the East Midlands, UK has also shown disappointing rates of compliance.

During 1992-93 a total of 1828 employees aged 41-65 were sent a letter explaining the study and inviting them to participate. Posters were put up at the site and the firm's medical department answered enquiries. Employees who agreed were sent a Haemoccult pack to provide samples for testing on three separate days. Positive tests were repeated after dietary restrictions (no red meat, black pudding, cauliflower, cabbage, spinach, radishes, parsnip, broccoli, or bananas) and, if still positive colonoscopy was offered. In all, 465 employees (25.4\%) completed three Haemoccult tests. The rate of compliance was not significantly different between men (425/1703) and women (40/125). Men aged 51-60 were more likely to comply than men aged $41-50$ or 61-65. Among women compliance rates were similar at ages 41-50 and 51-60. There were only seven women aged 61-65 and none of them completed a series of occult blood tests. Compliance was better among managers $(28.6 \%)$ than non-managers $(23.5 \%)$ especially in the youngest age group (41-50).

Four occult blood series $(0.9 \%)$ gave a positive result and one remained positive after dietary restriction. This positive test led to the discovery of a $1 \mathrm{~cm}$ pedunculated polyp in the splenic flexure. After colonoscopic removal the tumour proved to be a tubular adenoma with mild dysplasia and complete excision margins. The financial cost of screening in 1993 was $£ 6180$ (testing kits £580, staff costs £5000, colonoscopy £600).

The uptake of screening in this company based programme was low and similar to that achieved in some general practice studies. More intense presentation of the case for screening might increase uptake but older and non-managerial employees might be the least likely to consent.

A Postgraduate Medical Journal 2003;79:646-649. 